\title{
Development and evaluation of miconazole mucoadhesive tablets for oropharyngeal candidiasis
}

\author{
Qiong Jin ${ }^{1}$, Wei Chen ${ }^{1}$ and Wan $\mathrm{Wu}^{2 *}$ \\ ${ }^{1}$ Department of Implantation, School \& Hospital of Stomatology, Wenzhou Medical University, ${ }^{2}$ Department of Stomatology, The \\ First Affiliated Hospital of Wenzhou Medical University, Wenzhou 325000, China
}

*For correspondence: Email: wuwanww@hotmail.com; Tel/Fax: 0086-577-55578020

\begin{abstract}
Purpose: To develop mucoadhesive tablets containing miconazole (MCZ) for the treatment of oropharyngeal candidiasis, using chitosan and hydroxypropyl methylcellulose (HPMC) as mucoadhesive polymers.

Methods: Mucoadhesive tablets were formulated and optimized using a 23 factorial design and direct compression method. The independent variables were compression force and concentrations of chitosan and HPMC, while mucoadhesion time and in vitro drug release were dependent variables. Tablet characterization was carried out by evaluating hardness, thickness, tablet weight variation, content uniformity, friability and in vitro drug release at salivary $\mathrm{pH}(\mathrm{pH} 6.8)$.

Results: The tablets showed good mucoadhesion for an extended period (8 h), and their physical characteristics were within acceptable ranges. Drug release ranged from $60.5 \%$ to $80.8 \%$.

Conclusion: These results indicate that the mucoadhesive MCZ tablets formulated with chitosan and HPMC possess potential for the development of therapeutic preparations for management of oropharyngeal candidiasis.
\end{abstract}

Keywords: Miconazole, Oropharyngeal candidiasis, Factorial design, Mucoadhesion, Chitosan, Drug release

Tropical Journal of Pharmaceutical Research is indexed by Science Citation Index (SciSearch), Scopus, International Pharmaceutical Abstract, Chemical Abstracts, Embase, Index Copernicus, EBSCO, African Index Medicus, JournalSeek, Journal Citation Reports/Science Edition, Directory of Open Access Journals (DOAJ), African Journal Online, Bioline International, Open-J-Gate and Pharmacy Abstracts

\section{INTRODUCTION}

Oral candidiasis or oropharyngeal candidiasis (OPC) is an infection of the mucous membrane of the mouth by Candida species of yeast [1]. Candida albicans, a normal component of the oral flora, is the most prominent causative agent of OPC. Oral candidiasis or oropharyngeal candidiasis (OPC) may be classified as primary, in which only the mouth and perioral tissues are involved, or secondary, in which other tissues are also infected $[2,3]$.

The oral route is the most acceptable and preferred route of administration of many drugs.
However, first pass metabolism and enzymatic degradation constitute major challenges to oral drug delivery system. Thus the absorptive oral mucosa has become an attractive alternative site for drug delivery [4]. Mucoadhesive drug delivery systems overcomes some of the disadvantages associated with swallowing of drugs, and are important routes of administration of drugs in various dosage forms such as gels, ointments, patches and tablets [5].

Miconazole (MCZ) is a broad-spectrum antifungal agent and first-line antibiotic used for the prophylactic treatment of oral and vaginal candidiasis. It is available under the brand name 
Daktarin $^{\circledR}$, an oral topical gel. The major disadvantage of this gel is that it must be applied three-to-four times a day for 14 days. The requirement for repeated administration leads to patient non-compliance. Furthermore, the rapid release of the drug from the gel causes a rapid decline in the drug concentration to sub-therapeutic levels [6]. Considering these drawbacks, there is a need for development of a sustained- or controlled-release buccal mucoadhesive formulation that can be applied locally or topically for treatment of oral candidiasis. To achieve better therapeutic effect it is necessary to attain adequate oral MCZ concentration for extended periods of time.

\section{EXPERIMENTAL}

\section{Materials}

Miconazole (MCZ) was purchased from (Baoji, Shaanxi,Co. Ltd, China. Chitosan, HPMC microcrystalline cellulose (MCC), lactose, colloidal silicon dioxide, and magnesium stearate were products of Sigma Aldrich (St. Louis, MO, USA).

\section{$2^{3}$ factorial design for the development of mucoadhesive tablets}

Mucoadhesive (MCZ) tablets were developed with a full three-factor factorial design at two levels. The independent variables were the chitosan concentration (A), HPMC concentration $(B)$, and compression force (C), while the dependent variables were the mucoadhesion time (Y1) and drug release from the tablets (Y2). Details of these variables, along with their corresponding high and low values, are presented in Table 1. Optimization of the formulation was carried out based on statistical analysis using a $2^{3}$ full-factorial approach. The interaction between the dependent and interdependent variables was determined by contour plots [7].

Table 1: Independent and Dependent Variables

\begin{tabular}{|c|c|c|}
\hline \multirow{2}{*}{\multicolumn{3}{|c|}{$\begin{array}{l}\text { Variable } \\
\text { Independent }\end{array}$}} \\
\hline & & \\
\hline Chitosan & 50 & 75 \\
\hline concentration (mg; A) & & \\
\hline $\begin{array}{l}\text { HPMC concentration } \\
(\mathrm{mg} ; \mathrm{B})\end{array}$ & 25 & 35 \\
\hline $\begin{array}{l}\text { Compression force } \\
\text { (ton; C) }\end{array}$ & 3 & 6 \\
\hline $\begin{array}{l}\text { Dependent } \\
\text { Mucoadhesion time } \\
\text { (Y1) } \\
\% \text { drug release (Y2) }\end{array}$ & & \\
\hline
\end{tabular}

\section{Preparation of mucoadhesive tablets}

Direct compression approach was used for the preparation of mucoadhesive tablets. Weighed quantities of ingredients were sifted through a \# 60 sieve to ensure homogeneity. The sifted material was then mixed uniformly. Round 16$\mathrm{mm}$ punch and die was used for the compression of the tablets. The weight of each tablet was adjusted to $200 \mathrm{mg}$. Table 2 summarizes the composition of all the batches of mucoadhesive tablets.

Table 2: Formulation of mucoadhesive tablets

\begin{tabular}{rccccc}
\hline & \multicolumn{3}{c}{ Factor } & \multicolumn{2}{c}{ Response } \\
Code & $\boldsymbol{A}$ & $\boldsymbol{B}$ & $\boldsymbol{C}$ & Y1 & Y2 \\
\hline F1 & -1 & -1 & -1 & 5.0 & 72.87 \\
F2 & +1 & -1 & +1 & 4.0 & 60.54 \\
F3 & -1 & +1 & -1 & 3.5 & 61.15 \\
F4 & +1 & +1 & +1 & 5.5 & 73.80 \\
F5 & +1 & +1 & -1 & 8.0 & 80.82 \\
F6 & -1 & +1 & +1 & 7.5 & 66.54 \\
F7 & -1 & -1 & -1 & 6.0 & 69.87 \\
F8 & +1 & -1 & +1 & 6.5 & 72.35 \\
\hline
\end{tabular}

\section{Evaluation of mucoadhesive tablets}

\section{Weight variation}

This test was performed on 20 tablets by weighing individual tablets and calculating the average weight of the tablets [8]. The limit of weight variation was based on the US Pharmacopeial Convention (USP).

\section{Diameter and thickness}

Vernier caliper was used for the measurement of thickness and diameter at 3 different positions of 10 tablets [8].

\section{Hardness}

Tablet hardness was assessed by Monsanto hardness test apparatus [8].

\section{In vitro dissolution}

In vitro dissolution of mucoadhesive formulations was determined based on the solubility profile of the MCZ. The drug exhibited excellent solubility at higher $\mathrm{pH}$. Hence dissolution was performed in a phosphate buffer of $\mathrm{pH} 6.8$ at $37.0 \pm 0.5{ }^{\circ} \mathrm{C}$ using USP type II apparatus at $100 \mathrm{rpm}$. MCZ release was determined spectrophotometrically at $247.5 \mathrm{~nm}$. Samples $(5 \mathrm{ml})$ were withdrawn at specified time intervals and an equal volume of fresh buffer was added to the dissolution medium to maintain the sink condition. 


\section{Evaluation of in vitro mucoadhesion time}

Mucoadhesion time was determined on buccal mucosa isolated from a goat. The buccal mucosa was cleansed by rinsing it several times with physiological saline. A 5-cm patch of the mucosa was isolated and placed on a glass slide, and a tablet was placed on top of the mucosa. This slide was completely immersed in the saline solution, and the time required for the tablet to detach from the buccal mucosa was taken as the mucoadhesion time.

\section{Statistical analysis}

Design expert software (Version 6.0.8; Stat Ease.) was used for statistical analysis to generate polynomial equations.

\section{RESULTS}

\section{Physicochemical characteristics of the tablets}

The results obtained from physical evaluation of the tablets are shown in Table 3 . The diameter of the tablets ranged from $15.8 \pm 0.5$ to $16.3 \pm 1.0$ $\mathrm{mm}$, which were within acceptable range. There were no significant weight variations among the tablets (weights ranged from $198 \pm 3$ to $201 \pm 3$ $\mathrm{mg}$ ). The compression of tablets was carried out at 3-ton and 6-ton compression forces. Variations in hardness were observed due to difference in compression force during tablet compression. Batches with a 6-ton compression force had hardness ranging from $1.9 \pm 1.0$ to $3.1 \pm 1.0$ $\mathrm{kg} / \mathrm{cm}^{2}$. Greater hardness was found in tablets compressed with 6-ton force, when compared to batches subjected to 3-ton compression force $\left(1.3 \pm 1.0\right.$ to $\left.1.6 \pm 1.0 \mathrm{~kg} / \mathrm{cm}^{2}\right)$.

A direct relationship was found between compression force and hardness of tablets. However, compression force was inversely related to tablet thickness. Batches with a 3-ton force had a higher thickness $(3.2 \pm 1.0$ to $3.8 \pm$ $3.0 \mathrm{~mm})$ than batches with 6 -ton force $(2.9 \pm 2.0$ to $3.1 \pm 2.0 \mathrm{~mm}$ ). Tablets compressed with 3-ton and 6-ton compression forces showed less than $1 \%(\mathrm{w} / \mathrm{w})$ friability, which is the acceptance criterion recommended by USP. Overall, all the formulations had pharmaceutically acceptable physical properties.

From statistical analysis (Table 5), it was found that the selected model (2F1) was statistically significant based on model F-value of 223.78 . The $R^{2}$ value of 0.9798 for response $Y 2$ points at 2FI model (Table 4). In addition, factor $Y 1$ was found to be statistically significant $(p=0.0001)$, as shown in Table 4.

Table 3: Physicochemical characteristics of the mucoadhesive tablets

\begin{tabular}{lccccc}
\hline Formulation & Weight $\mathbf{( m g )}$ & $\begin{array}{c}\text { Thickness } \\
(\mathbf{m m})\end{array}$ & $\begin{array}{c}\text { Diameter } \\
(\mathbf{m m})\end{array}$ & $\begin{array}{c}\text { Hardness } \\
\left(\mathbf{k g} / \mathbf{c m}^{2}\right)\end{array}$ & Friability \\
\hline F1 & $200.0 \pm 3.0$ & $5.0 \pm 2.0$ & $16.0 \pm 1.0$ & $2.0 \pm 1.0$ & 1.0 \\
F2 & $199.0 \pm 3.0$ & $4.8 \pm 2.0$ & $15.9 \pm 0.0$ & $1.8 \pm 1.0$ & 0.8 \\
F3 & $201.0 \pm 1.0$ & $4.9 \pm 1.0$ & $16.1 \pm 2.0$ & $2.2 \pm 1.0$ & 0.8 \\
F4 & $198.0 \pm 2.0$ & $5.2 \pm 2.0$ & $16.0 \pm 1.0$ & $1.7 \pm 1.0$ & 0.9 \\
F5 & $199.0 \pm 3.0$ & $5.3 \pm 2.0$ & $15.8 \pm 1.0$ & $1.7 \pm 1.0$ & 0.8 \\
F6 & $200.0 \pm 1.0$ & $5.5 \pm 2.0$ & $16.1 \pm 1.0$ & $2.8 \pm 1.0$ & 0.3 \\
F7 & $201.0 \pm 2.0$ & $5.7 \pm 2.0$ & $15.9 \pm 2.0$ & $2.4 \pm 1.0$ & 0.5 \\
F8 & $199.0 \pm 3.0$ & $3.5 \pm 3.0$ & $16.0 \pm 1.0$ & $1.4 \pm 1.0$ & 0.7 \\
\hline
\end{tabular}

Table 4: Regression analysis for responses $Y 1$ and $Y 2$

\begin{tabular}{|c|c|c|c|c|c|c|}
\hline Models & $\mathbf{R}^{2}$ & Adjusted R ${ }^{2}$ & Predicted $\mathbf{R}^{2}$ & SD & Press & Remarks \\
\hline \multicolumn{7}{|c|}{ Response Y1 } \\
\hline Linear & 0.8021 & 0.7921 & 0.5217 & 3.63 & 22.20 & \\
\hline $2 F I$ & 0.9987 & 0.9955 & 0.9865 & 1.74 & 55.00 & Suggested \\
\hline Quadratic & 0.6261 & 0.7172 & 0.7225 & 0.35 & 22.30 & \\
\hline Cubic & 0.9120 & 0.6963 & 0.7912 & 2.63 & 49.20 & \\
\hline \multicolumn{7}{|l|}{ Response Y2 } \\
\hline Linear & 0.6687 & 0.6262 & 0.7763 & 4.80 & 10.00 & \\
\hline $2 F I$ & 0.9798 & 0.9720 & 0.9361 & 2.07 & 16.18 & Suggested \\
\hline Quadratic & 0.9011 & 0.8617 & 0.8488 & 3.97 & 10.00 & ......... \\
\hline Cubic & 0.9114 & 0.8625 & 0.8290 & 5.50 & 13.36 & $\ldots \ldots \ldots$ \\
\hline \multicolumn{7}{|c|}{$\begin{array}{l}\text { Regression equations fitted to the models } \\
Y 1=+54.66+27.34 A+8.34 B-7.33 C \\
Y 2=+78.22+5.33 A-1.14 B-2.14 C\end{array}$} \\
\hline
\end{tabular}


Table 5: Analysis of variance of Models $\mathrm{Y} 1$ and $\mathrm{Y} 2$

\begin{tabular}{lccccc}
\hline Source & DF & Sum of squares & Mean square & F value & $\boldsymbol{P}$-value \\
\hline Model for $\mathbf{Y 1}$ & 3 & 3859.38 & 1286.46 & 512.35 & $<\mathbf{0 0 1}$ \\
A & 1 & 3003.13 & 3003.13 & 961.00 & $\mathbf{0 . 0 0 0 1}$ \\
B & 1 & 153.12 & 153.12 & 49.00 & $\mathbf{0 . 0 0 2}$ \\
C & 1 & 703.13 & 703.13 & 225.00 & $\mathbf{0 . 0 0 1 1}$ \\
Model for Y2 & 3 & 409.74 & 136.58 & 223.78 & $\mathbf{0 . 0 0 0 1}$ \\
A & 1 & 300.74 & 300.74 & 264.73 & $\mathbf{0 . 0 0 0 1}$ \\
B & 1 & 33.17 & 33.17 & 29.20 & $\mathbf{0 . 0 0 2 3}$ \\
C & 1 & 75.83 & 75.83 & 66.75 & $\mathbf{0 . 0 0 1 1}$ \\
\hline
\end{tabular}
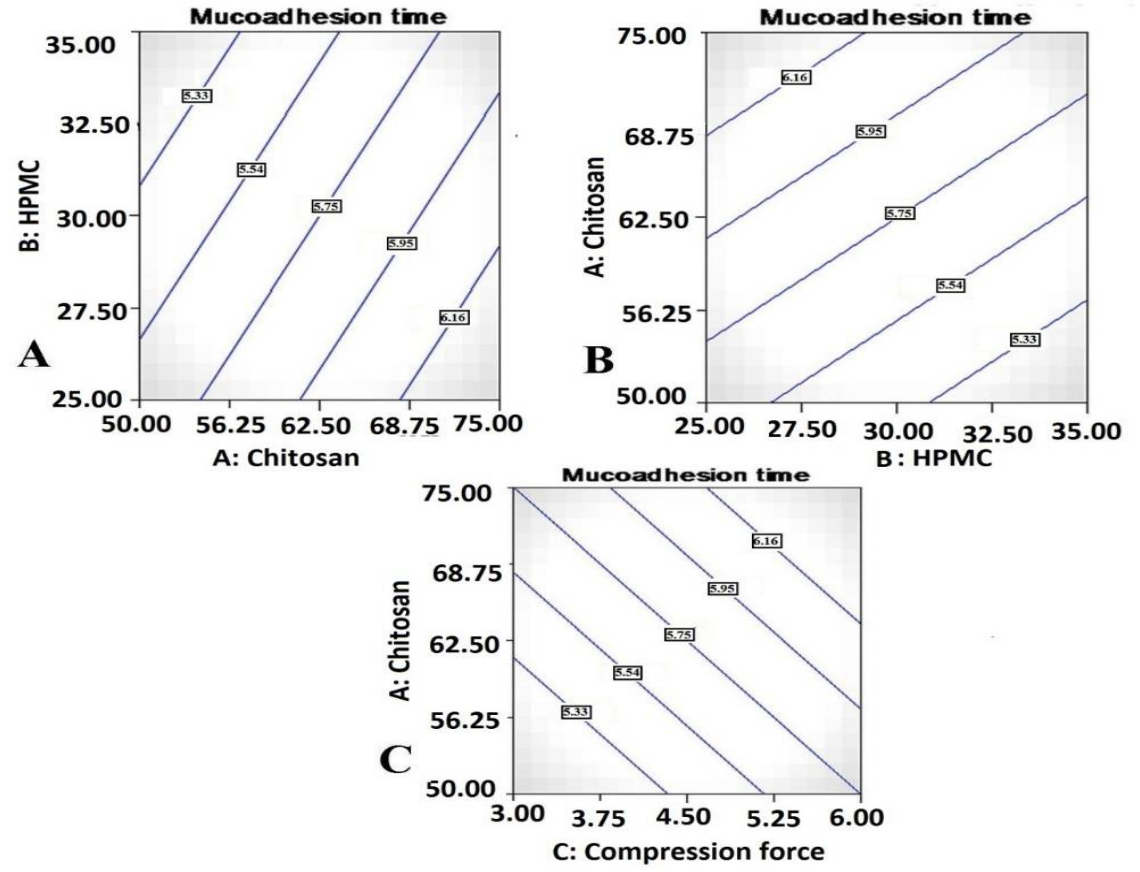

Figure 1: Effect of (A) chitosan, (B) HPMC, and (C) compression force on tablet mucoadhesion. $D R=$ Drug release
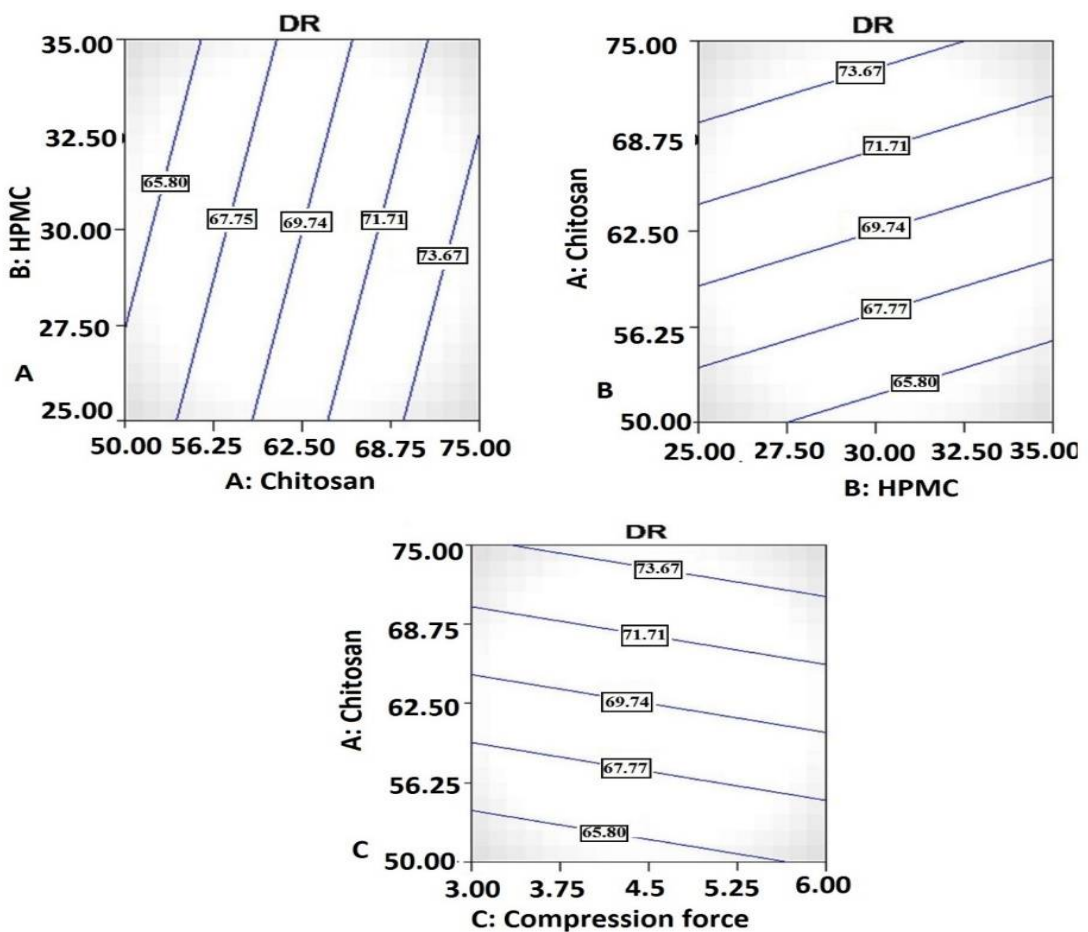

Figure 2: Effect of (A) chitosan, (B) HPMC, and (C) compression force on tablet drug release 
Figure 1 shows the effects of chitosan, HPMC and compression force (independent variables) on mucoadhesion time, while Figure 2 shows their effects on drug release.

\section{DISCUSSION}

The in vitro mucoadhesion time of the tablets was determined at the salivary $\mathrm{pH}$ of 6.8 in phosphate-buffered saline. The mucoadhesive tablets showed increased mucoadhesion ranging from 2 to 8 h. Generally, increased mucoadhesion is preferred in this type of drug delivery system.

Chitosan is the most widely used mucoadhesive polymer in the pharmaceutical industry, in various dosage forms such as transdermal bioadhesive patches, tablets, capsules, fast disintegrating films, and mucoadhesive films. Thus, chitosan was used chosen in this study for imparting mucoadhesive property to the tablets [10]. The contour plot obtained indicated that mucoadhesion time was significantly increased by increases in the concentration of chitosan. The increase in mucoadhesion period to 8 hours is suitable for treatment of patients with OPC. HPMC, a hydrophilic polymer with mucoadhesive properties, was used to improve the mucoadhesive properties of chitosan. It has been demonstrated that the combination of chitosan and HPMC is important for improving tablet mucoadhesion [11]. This is consistent with the contour plot obtained in the present study, which showed clearly that mucoadhesion was directly proportional to HPMC concentration. Obviously, the hydrophilic nature of the polymer imparted significant mucoadhesive properties on the tablet formulations.

The increase in direct compression force from 3ton to 6-ton led to statistically significant increase in the mucoadhesion time of the tablets. The model F-value of 512.35 clearly shows that the 2F1 model was statistically significant. Positive and negative coefficients from the equation indicate the synergistic and antagonistic effects of the variables respectively [9]. The suggested model for drug release $\mathrm{Y} 2$ was $2 \mathrm{FI}$ which had a correlation coefficient $R^{2}$ of 0.9987 . This model was also statistically significant, with all independent variables being statistically significant $[\mathrm{A}(p=0.0001), \mathrm{B}(p=0.002)$, and C $(p=0.0011)]$.

Chitosan and HPMC had a combined effect on MCZ drug release from the mucoadhesive tablets. The contour plots revealed a significant and inverse relationship between chitosan and
HPMC concentrations, and drug release from the tablets. Due to the controlled-release property of both chitosan and HPMC, and increase in compression force, MCZ drug release was reduced in the oral cavity.

\section{CONCLUSION}

Mucoadhesive tablets of MCZ formulated using chitosan and HPMC polymers significantly decreased drug release in the oral cavity. Thus, this formulation could be an efficient drug delivery technology for the treatment of OPC, since the increased mucoadhesion of the tablets would be helpful in retarding the progression of OPC. The results obtained in this study suggest that mucoadhesive drug delivery has a promising potential in the treatment and control of OPC.

\section{DECLARATIONS}

\section{Acknowledgement}

The authors are very thankful to the Department of Stomatology, Wenzhou Medical University, Wenzhou 325000, China for providing the facilities for the conduct of this research.

\section{Conflict of Interest}

No conflict of interest associated with this work.

\section{Contribution of Authors}

The authors declare that this work was done by the authors named in this article and all liabilities pertaining to claims relating to the content of this article will be borne by them.

\section{Open Access}

This is an Open Access article that uses a funding model which does not charge readers or their institutions for access and distributed under the terms of the Creative Commons Attribution License (http://creativecommons.org/licenses/by/ 4.0) and the Budapest Open Access Initiative (http://www.budapestopenaccessinitiative.org/rea d), which permit unrestricted use, distribution, and reproduction in any medium, provided the original work is properly credited.

\section{REFERENCES}

1. Shin ES, Chung SC, Kim YK. The relationship between oral Candida carriage and the secretor status of blood group antigens in saliva. Oral Surg Oral Med Oral Pathol Oral Radiol Endod 2003; 96: 48-53.

Trop J Pharm Res, October 2017; 16(10): 2329 
2. Epstein JB. Diagnosis and treatment of oropharyngeal candidiasis. Oral Maxillofac Surg Clin North Am 2003; 15: 91-102.

3. Vazquez JA, Sobel JD. Mucosal candidiasis. Infect Dis Clin North Am 2002; 16: 793-820.

4. Miller NS, Johnston TP. The use of mucoadhesive polymers in buccal drug delivery. Adv Drug Deliv Rev 2005; 57: 1666-1691.

5. Shojaei AH. Buccal mucosa as a route for systemic drug delivery: A review. J Pharm Pharmaceut Sci 1998; 1:1530.

6. Kobayashi D, Kondo K, Uehara $N$. Endogenous reactive oxygen species is an important mediator of miconazole antifungal effect. Antimicrob Agent Chemother 2002; 46: 3113-3117.

7. Chaudhary H, Gauri S, Rathee P, Kumar V. Development and optimization of fast dissolving oro-dispersible films of granisetron $\mathrm{HCl}$ using Box-Behnken statistical design. Bull. Fac Pharm, Cairo Univ 2013; 51: 193-201.
8. Elzatahry AA, Mohy Eldin MS. Preparation and characterization of metronidazole loaded chitosan nanoparticles for drug delivery application. Polym Adv Technol 2008; 19: 1787-1791

9. Yasser EM, Sami N. Hydrophilic matrices: Application of Placket-Burman screening design to model the effect of POLYOX-carbopol blends on drug release. Int J Pharm 2008; 309: 163-170.

10. Papadimitriou S, Bikiaris D, Avgoustakis K, Karavas E, Georgarakis M. Chitosan nanoparticles loaded with dorzolamide and pramipexole. Carbohyd Polym 2008; 73: 44-54.

11. Tarek A. Ahmed, Khalid M. El-Say. Development of alginate-reinforced chitosan nanoparticles utilizing $W / O$ nanoemulsification/internal crosslinking technique for transdermal delivery of rabeprazole. Life Sci 2014; 110: 35-43. 